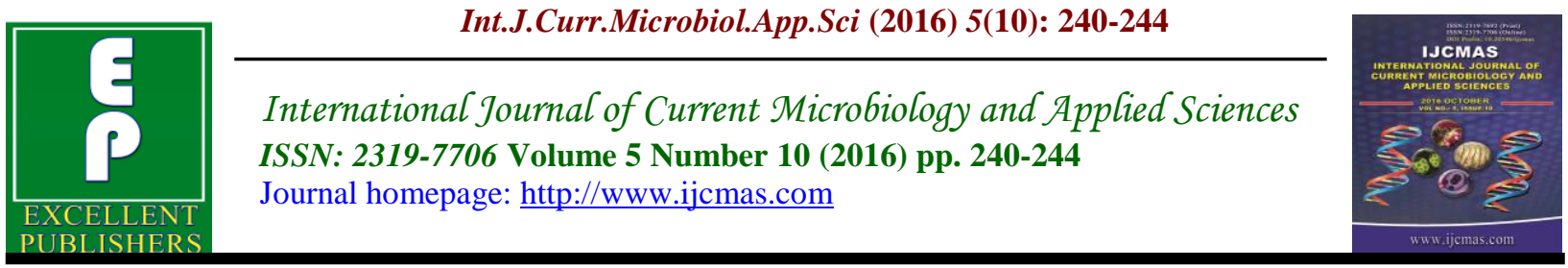

Original Research Article

http://dx.doi.org/10.20546/ijcmas.2016.510.026

\title{
Enzyme-Linked Immunosorbent Assay for Detection of Aspergillus fumigatus Antibodies
}

\author{
Raksha Singh ${ }^{1}$, Gurjeet Singh ${ }^{2} *$ and A.D. Urhekar ${ }^{1}$ \\ ${ }^{1}$ Department of Microbiology, MGM Medical College and Hospital, MGM Institute of Health \\ Sciences, Kamothe, Navi Mumbai-410209, Maharashtra, India \\ ${ }^{2}$ Department of Microbiology, NC Medical College and Hospital, Israna, \\ Panipat-132107, Haryana, India \\ *Corresponding author
}

A B S T R A C T

Keywords

Aspergillosis,

Aspergillus

fumigatus,

Antibody,

Enzyme Linked

Immunosorbent

Assay.

Article Info

Accepted:

12 September 2016

Available Online:

10 October 2016

Aspergillus species are ubiquitous fungi, commonly found in soil, water and decaying matter. Generally humans get infection through inhalation of spores. The spores come in lung and then disseminate to cause systemic aspergillosis. This prospective and experimental study was carried out at Department of Microbiology, MGM Medical College and Hospital, Navi Mumbai. Total 86 blood samples were included in this study. ELISA test was done for detection of IgM antibodies of A. fumigatus. IgM antibody of A. fumigatus was detected by ELISA test in patient serum was 18 out of 86 $(20.93 \%)$. ELISA method found more sensitive and specific method for detection of invasive aspergillosis.

\section{Introduction}

Invasive pulmonary aspergillosis (IPA) is a major threat to leukemic patients with cytotoxic therapy-induced neutropenia and transplant recipients receiving high-dose corticosteroid therapy. Since the diagnosis of IPA in an early stage is seldom possible and the mortality rate is very high (Bodey et al., 1992), successful treatment is directly related to early diagnosis (Aisner et al., 1977).

Serological tests are useful in the diagnosis of allergic and mycetomal forms of

aspergillosis in immunocompetent patients. The usefulness of these tests in invasive forms of aspergillosis in immunocompromised patients is less well established. Agar gel double diffusion (AGDD) is the principal serological method used at present (Coleman et al., 1972; English et al., 1967; Longbottom et al., 1964; Schaefer et al., 1976). Precipitins to Aspergillus fumigatus can be detected in the serum of almost all patients with the mycetomal form of aspergillosis. In contrast, serum from patients with allergic 
aspergillosis often has to be concentrated before precipitins can be detected. Other less time-consuming methods that have been evaluated for the rapid detection of $A$ fumigatus antibodies, included counterimmunoelectrophoresis (Dee, 1975; Warnock, 1977), passive haemagglutination (Gold et al., 1980), radioimmunoassay (Bardana et al., 1975; Marier et al., 1979) and indirect immunofluorescence (Warnock et al., 1974, 1981).

A recently developed sandwich enzymelinked immunosorbent assay (ELISA) allowed the detection of low levels of circulating Aspergillus galactomannan (GM) in sera from patients at high risk of IPA, but the increase in sensitivity was also associated with false-positive results in up to $8 \%$ of the serum samples. Since IPA is predominantly a pulmonary infection in immunocompromised patients, detectable antigen levels may be present in BAL fluid samples from patients suspected of having IPA and therefore may be of use for the diagnosis of IPA.

\section{Materials and Methods}

Study type: Prospective and experimental.

Period of study: The study was carried out over a period of 12 months with effect from January 2015 to December 2015.

Place of study: Department of Microbiology, MGM Medical College and Hospital, Kamothe, Navi Mumbai.

Number of samples: 86 .

Study group: 86 Patient attending IPD and OPD, MGM Medical College and hospital, Navi Mumbai.

Inclusion criteria: Blood samples of patients with chronic purulent exudates in sputum samples.
Exclusion criteria: Blood samples of patients which do not show any pus cells in sputum samples were excluded from studies.

Statistical analysis: Chi Square test, Fischer's (F) test and t test was used for testing the hypothesis.

\section{Ethical Clearance}

The study was cleared by Institutional Ethics committee of MGM Institute of Health Sciences, Navi Mumbai and written consent from the patients was taken prior to collection of samples.

\section{Sample Collection}

Blood samples from patient attending tertiary care hospital were collected in plain sterile tube by taking all aseptic precautions and properly labelled. After 30 minutes of collection the samples were centrifuged at 3000 RPM for 5 minutes using centrifuge machine and serum separated and stored at $5-8^{\circ} \mathrm{C}$ in refrigerator.

\section{Results and Discussion}

Sensitivity and specificity of ELISA test was $100 \%$, however sensitivity- $66.67 \%$ and specificity $100 \%$ for culture.

ELISA test for Aspergillus IgM antibodies were carried out on 86 blood samples of those patients, whose sputum samples showed purulent exudates. This means that there is lower respiratory tract infection and there is presence of $\operatorname{IgM}$ antibody in 18 blood samples (20.93\%) which is indicative of sensitization or exposure to Aspergillus fungus elements.

SDA culture on same number of sputum samples with purulent exudates, showed culture positivity in 12 out of 86 sputum 
samples (13.95\%).IgM Antibody present but no fungal growth on SDA in 6 sputum samples could be because of prior treatment which will inhibit growth.

Table.1 Showing comparison of two methods for detection of A. fumigatus.

\begin{tabular}{|l|l|l|}
\hline Methods & No. of samples & Positive \\
\hline ELISA test & 86 & $18(20.93 \%)$ \\
\hline Culture on SDA & 86 & $12(13.95 \%)$ \\
\hline \multicolumn{2}{|l|}{ Chi square $=1.02, \mathrm{dg}=1, \mathrm{P}$ value $>0.05$, Not significant } \\
\hline
\end{tabular}

Table.2 Calculation of sensitivity and specificity of two methods for detection of A. fumigatus

\begin{tabular}{|l|l|l|}
\hline Methods & Positive & Negative \\
\hline ELISA test & 18 & 68 \\
\hline Culture on SDA & 12 & 74 \\
\hline
\end{tabular}

Fig.1 Showing methods for detection of A. fumigatus.

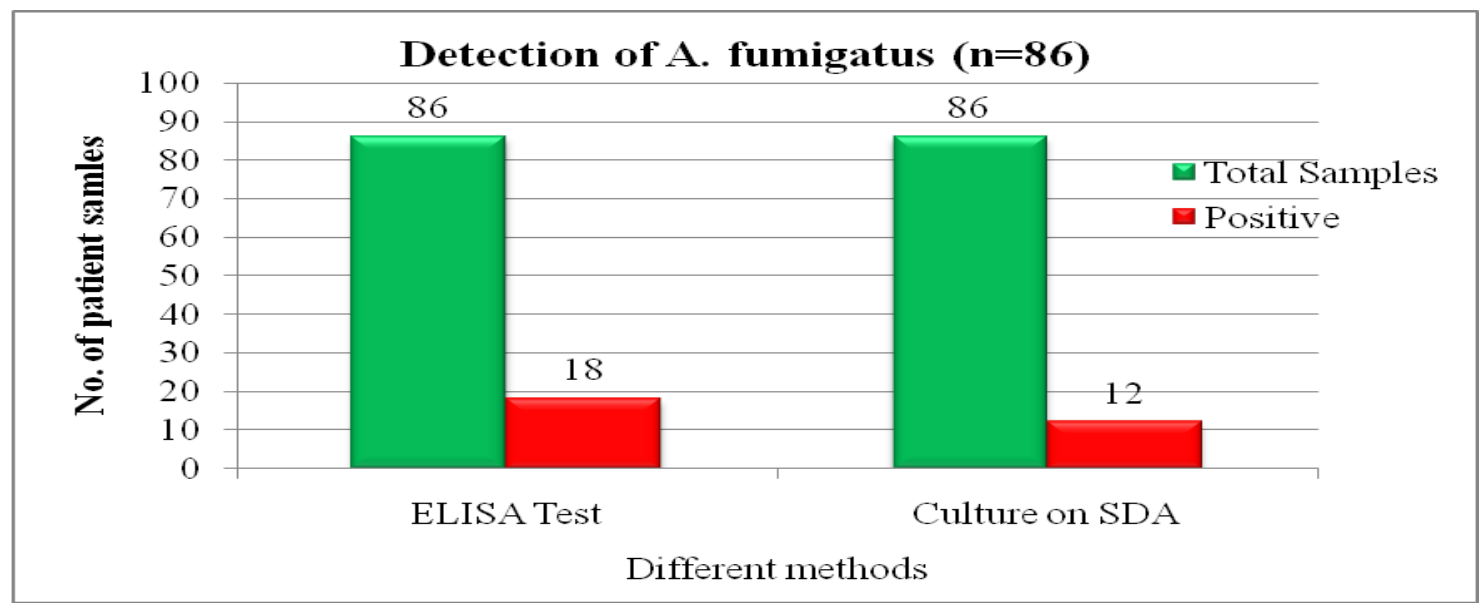

Fig.2 Showing sensitivity of different methods for detection of A. fumigatus.

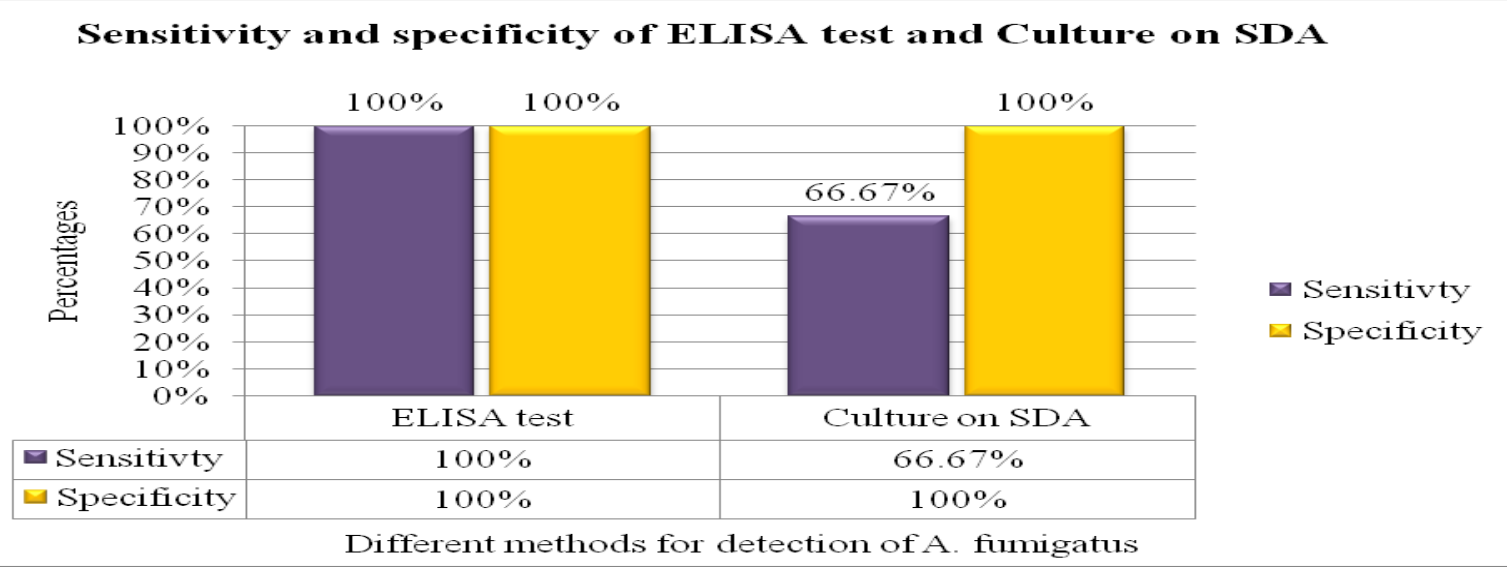


Sensitivity of ELISA was $100 \%$ but that of culture was $66.67 \%$ and specificity of both ELISA and Culture was $100 \%$. Our IgM positivity results $(20.93 \%)$ compared well with study of Kumar et al., (1989) from Manipal, India reported $20 \%$ positivity. Shahid et al., (2001) in 2001 reported $30.6 \%$ positivity. Similarly our culture positivity $(13.95 \%)$ compares well with that of Shahid et al., (2001) (14.7\%).

Findings of foreign studies was Richardson et al., (1982) (53.57\%), Florent et al., (2006) $63.6 \%$ and $89.7 \%$, Sabetta et al., (2000) reported 57.89\%, Maesaki S et al., (1999). Higher antibody percentages were reported by foreign workers from different parts of world. There can be higher chance of subclinical exposure to aspergilli.

In conclusion, this ELISA is a sensitive, specific, and easily performed assay for circulating Aspergillus antibody that should facilitate early diagnosis of invasive aspergillosis. It is concluded that prevalence of Aspergillosis is quite high. Culture and serological test should be performed in conjunction to establish the diagnosis. Isolation of aspergilli by culture from lesion (pulmonary and other lesion) is desirable but may not be possible in each and every case. Sample /exudates collection may be improper/ inadequate. Prior treatment can inhibit growth on culture media. Deep seated lesions may not yield sample. Hence for diagnosis of aspergillosis all diagnostic methods are necessary but more wattage should be given serology (Ig M) antibodies for ongoing infection.

\section{References}

Aisner, J., S.C. Schimpff, and P.H. Wiernik. 1977. Treatment of invasive aspergillosis: relation of early diagnosis and treatment to response. Ann. Intern. Med., 86: 539-543.

Bardana, E.J. Jr., Gerber, J.D., Craig, S., Cianciulli, F.D. 1975. The generaland specific humoral immune response to pulmonary aspergillosis. Am. Rev. Respir. Dis., 112: 799-805.

Bodey, G., B. Bueltmann, W. Duguid, D. Gibbs, H. Hanak, M. Hotchi, G. Mall, P. Martino, F. Meunier, S. Milliken, S. Naoe, M. Ohidaira, D. Scevola, and J. van't Wout. 1992. Fungal infections in cancer patients: an international autopsy survey. Eur. J. Clin. Microbiol. Infect. Dis., 11: 99-109.

Coleman, R.M., Kaufman, L. 1972. Use of the immunodiffusion test in the serodiagnosis of aspergillosis. Appl. Microbiol., 23: 301-8.

Dee, T.H. 1975. Detection of AspergiUlus fumigatus serum precipitins by counterimmunoelectrophoresis. $J$. Clin. Microbiol., 2: 482-5.

English, M.P., Henderson, A.H. 1967. Significance and interpretation of laboratory tests in pulmonary aspergiliosis. J. Clin. Pathol., 20: 8324.

Florent, M., Katsahian, S., Vekhoff, A., Levy, V., Rio, B., Marie, J., Bouvet, A., Cornet, M. 2006. Prospective Evaluation of a Polymerase Chain Reaction-ELISA Targeted to Aspergillus fumigatus and Aspergillus flavus for the Early Diagnosis of Invasive Aspergillosis in Patients with Hematological Malignancies. J. Infect. Dis., 193: 741-747.

Gold, J.W.M., Fisher, B., Yu, B., Chein, N., Armstrong, D. 1980. Diagnosis of invasive aspergiliosis by passive haemagglutination assay of antibody. J. Infect. Dis., 142: 87-94.

Kumar, A.A., Sahu, R.C., Subbannayyar, K.K., Jyothirlata, Rau, P.V., 
Shivananda, P.G. 1989. Prevalence of antibodies to aspergilli in bronchial asthmatics. J. Postgrad. Med., 35: 203.

Latge, J.P., Kobayashi, H., Debeaupuis, J.P., Diaquin, M., Sarfati, J., Wieruszeski, J.M., et al. 1994. Chemical and immunological characterization of the extracellular galactomannan of Aspergillus fumigatus. Infect. Immun., 53: 5424-5433.

Longbottom, J.L., Pepys, J. 1964. Pulmonary aspergillosis: diagnostic and immunological significance of antigens and C-substance in Aspergillus fumigatus. J. Pathol. Bacteriol., 88: 141-5 1.

Maesaki, S., Kawamura, S., Hashiguchi, K., Hossain, M.A., Sasaki, E., Miyazaki, Y., Tomono, K., Tashiro, T., Kohno, S. 1999. Evaluation of sandwich ELISA galactomannan test in samples of positive LA test and positive Aspergillus antibody. Intern. Med., 38(12): 948-50.

Marier, R., Smith, W., Jansen, M,. Andriole, V.T. 1979. A solid-phase radioimmunoassay for the measurement of antibody to Aspergillus in invasive aspergiliosis. $J$. Infect. Dis., 140: 771-9.

Richardson, M.D., Stubbins, J.M., Warnock, D.W. 1982. Rapid enzyme-linked immunosorbent assay (ELISA) for Aspergillus fumigatus antibodies. $J$. Clin. Pathol., 35: 1134-1137.

Sabetta, J.R., Miniter, P., Andriole, V.T. 1985. The diagnosis of invasive aspergillosis by an enzyme-linked immunosorbent assay for circulating antigen. J. Infect. Dis., 152(5): 946953.

Schaefer, J.C., Yu, B., Armstrong, D. 1976. An Aspergilius immunodiffusion test in the early diagnosis of aspergillosis in adult leukemia patients. Am. Rev. Respir. Dis., 113: 325-9.

Shahid, M., Malik, A., Bhargava, R. 2001. Incidence of aspergillosis in chronic lung diseases. Indian J. Med. Microbiol., 19: 201-205.

Verweij, P.E., Stynen, D., Rijs, A.J.M.M., Pauw, B.E. De, Hoogkamp-Korstanje, J.A.A., Meis, J.F.G.M. 1995. Sandwich enzyme-immunoassay compared with Pastorex latex agglutination test for diagnosing invasive aspergillosis in immunocompromised patients. J. Clin. Microbiol., 33: 1912-1914.

Warnock, D.W. 1974. Indirect immunofluorescence test for the detection of AspergiUlus fumigatus antibodies. J. Clin. Pathol., 27: 911-2.

Warnock, D.W. 1977. Detection of Aspergillus fiumigatus precipitins: a comparison of counter immunoelectrophoresis and double diffusion. J. Clin. Pathol., 30: 388-9.

Warnock, D.W., Hann, E.M. 1981. Further evaluation of indirect immunofluorescence methods for detection of antibodies against Aspergillus fumigatus. Sabouraudia, 19: 49-54.

\section{How to cite this article:}

Raksha Singh, Gurjeet Singh and A.D. Urhekar. 2016. Enzyme-Linked Immunosorbent Assay for Detection of Aspergillus fumigatus Antibodies. Int.J.Curr.Microbiol.App.Sci. 5(10): 240244. doi: http://dx.doi.org/10.20546/ijcmas.2016.510.026 